\title{
EFFECT OF FUEL CHIPS ON CLADDING STRESS IN ZIRCALOY CLAD OXIDE FUEL RODS
}

(LWBR Development Program)

NOVEMBER 1978

CONTRACT EY-76-C-11-0014 


\section{DISCLAIMER}

This report was prepared as an account of work sponsored by an agency of the United States Government. Neither the United States Government nor any agency Thereof, nor any of their employees, makes any warranty, express or implied, or assumes any legal liability or responsibility for the accuracy, completeness, or usefulness of any information, apparatus, product, or process disclosed, or represents that its use would not infringe privately owned rights. Reference herein to any specific commercial product, process, or service by trade name, trademark, manufacturer, or otherwise does not necessarily constitute or imply its endorsement, recommendation, or favoring by the United States Government or any agency thereof. The views and opinions of authors expressed herein do not necessarily state or reflect those of the United States Government or any agency thereof. 


\section{DISCLAIMER}

Portions of this document may be illegible in electronic image products. Images are produced from the best available original document. 
EFFECT OF FUEL CHIPS ON CLADDING STRESS IN ZIRCALOY CLAD OXIDE FUEL RODS (LWBR Development Program)

J. F. Yerman

November, 1978

Contract EY-76-C-11-0014

Printed in the United States of America

Available From

National Technical Information Service

U. S. Department of Commerce 5285 Port. Royal Roa.

Springfield, Va. 22151

\section{NOTE}

This document is an interim memorandum prepared primarily for internal reference and does not represent a final expression of the opinion of Westinghouse. When this memorandum is distributed externally, it is with the express understanding that Westinghouse makes no representation as to completeness, accuracy; or usahility of information contained therein. 
'l'his report was prepared as an account of work sponsored by the United States Government. Neither the United States, nor the U. S. Department of Energy, nor any of their employees, nor any of their contractors, subcontractors, or their. employees, make any warranty, express or implied, or assumes any legal liability of responsibility for the accuracy, completeness or usefulness of any information, apparatus, product or process disclosed, or represents that its use would not infringe privately owned rights. 


\section{FOREWORD}

The Shippingport Atomic Power Station located in Shippinfport, Pennsylvania was the first large-scale, central-station nuclear power plant in the United States and the first plant of such size in the world operated solely to produce electric power. This program was started in 1953 to confirm the practical. application of nuclear power for large-scale electric power generation. It has provided much of the technology being used for design and operation of the commercial, central-station nuclear power plants now in use.

Subsequent to development and successful operation of the Pressurized Water Reactor in the DOE-owned reactor plant at the Shippingport Atomic Power Station, the Atomic Energy Commission in 1965 undertook a research and development program to design and build a Light Water Breeder Reactor core for operátion in the Shippingport Station.

The objective of the Light Water Breeder Reactor (LWBR) program has been to develop a technology that would significantly improve the utilization of the nation's nuclear fuel resources employing the well-established water reactor technology. To achieve this objective, work has been directed toward analysis, design, component tests, and fabrication of a water-cooled, thorium oxide fuel cycle breeder reactor for installation and operation at the Shippingport Station. The LWBR core started operation in the Shippingport Station in the Fall of 1977 and is expected to be operated for about 3 to 4 years. At the end of this period, the core will be removed and the spent fuel shipped to the Naval Reactors Expended Core Facility for a detailed examination to verify core performance including an evaluation of breeding characteristics.

In 1976, with fabrication of the Shippingport LWBR core nearing completion, the Energy Research and Development Administration established Lhe Advanced Water Breeder Applications (AWBA) program to develop and disseminate technical information which would assist U. S. industry in evaluating the LWBR concept for commercial-scale applications. The program will explore some of the problems that would be faced by industry in adapting technology confirmed in the LWBR program. Information to be developed includes concepts for commercial-scale prebreeder cores which would produce uranium-233 for light water breeder cores while producing electric power, improvements for breeder sores based on the technology developed to fabricate and operate the Shippingport LWBR core, and other information and techrology to aid in cvaluating commercial-scale application of the LWBR concept. 


\section{FOREWORD (Cont)}

All three development programs (Pressurized Waler Reactor, Light Waler Breeder Reactor, and Advanced Water Breeder Applications) have been administered by the Division of Naval Reactors with the goal of developing practical improvements in the utilization of nuclear fuel resources for generation of electrical energy using water-cooled nuclear reactors.

Technical information developed under the Shippingport, LWBR, and AWBA programs has been and will continue to be published in technical memoranda, one of which is this present report. 
I. INTRODUCTION

II. MECHANICAL TESTS 2

A. Crush Tests on Fuel Chips

B. Radial Stiffness Tests on Cladding

C. Strain Tests on Fuel Rod Cladding

III. FUEL ROD CLADDING ANALYSIS

A. Cladding Deformation and Bending Stress

B. Cladding Total Stresses at a Chip

IV. SUMMARY

ACKNOWLEDGEMENTS

REFERENCES

\section{LIST OF FIGURES}

Figure

$1 \quad$ Crush Force on Chips Between Flat Plates 13

$2 \quad$ Crush Force on Chips Between Curved Plates

Calculated Tensile Strains Compared to Measured Strains (Oulside Clad)

10 Calculated Tensile Strains Compared to Measured Strains (Inside Clad)

11 Cladding and Chip Interference Model

\section{LIST OF TABLES}

\section{Table}

Title

Page 
Lircaloy clad oxide fuel rods are subjected to a variety of core power transients. One of these, an up-power transient, can place a severe burden on the fuel rod cladding that would potentially lead to rupture if not properly allowed for during the fuel rod design and plant operation. The cladding stress during such a transient can be increased by the presence of fuel chips between the oxide fuel pellet and the cladding. An analysis procedure based on mechanical tests of fuel and cladding was developed that permits calculation of the stress increase due to chips, so that the stress penalty can be accommodated without unnecessary penalties to fuel rod performance. The method of evaluating the maximum cladding bending tensile stress near the chip is described and test data are presented to support the analysis method.

\section{EFFECT OF FUEL CHIPS ON CLADDING STRESS IN ZIRCALOY CLAD OXIDE FUEL RODS \\ (LWBR Development Program)}

J. F. Yerman

\section{INTRODUCTION}

The Light Water Breeder Reactor (LWBR) Program is developing, the technology to breed fissile material in a light water reactor in order to use nuclear fuel more effectively in thermal reactors. The fuel rods in LWBR contain cylindrical thoria and thoria-urania pellets in Zircaloy-4 tubing: The tubing is welded closed on both ends to form a water tight cladding for the pellets.

The fuel rods in LWBR were designed to operate without rupture of the cladding for the lifetime of the core, under conditions of either long periods of heat production at a constant power level (base load operation) or rapidy changing heat generation rates as occur during power transients in a load following power plant. Differential thermal expansion between the fuel and cladding during up-power transients can cause excessive stress in the cladding if the magnitude of power changes is not restricted. One of. the key aspects in determining the cladding stress is the fuel to cladding clearance (diametral gap) at the start of the transient since this initial gap, plus the power change, sets the fuel-cladding interference at the end of the transient. In addition, if fuel chips are present in the gap, then the cladding stresses (and deflection) will. he higher to accommodate the additional interference for a given power chànge. 
Early in the core operating lifetime, the fuel-clad gap is sufficiently large to allow the radial thermal expansion of the fuel without forcible contact. For this condition, the fuel can freely slide axially without causing interaction stresses in the clad. However, if numerous fuel chips are present in the gap, the axial thermal expansion of the fuel stack will be blocked to some degree and plastic strain of the cladding can occur.

The fuel rod performance considerations affected by the presence of chips are fuel rod elongation, cladding local circumferential and axial stresses, and fuel rod bowing. Tests on Zircaloy-4 cladding and sample fuel chips have been performed as part of the LWBR fuel element development program. Results of these tests have indicated that the radial force caused by fuel-cladding interference is sufficient to crush the chip and relieve some of the cladding stress. This report provides a summary of the test data, the methods used to culculate the amount of chip interference that can occur (including crushing), and the resulting calculated cläd circumferential tensile stresses that must bc considered in evaluation of the up-power transient.

The total stress situation for the cladding is a complicated function of fuel-cladding interaction, core power"; core power history, and pellet and cladding geometry. The analysis for the effect of chips on cladding rupture assumes that the major stresses due to fuel-cladding interaction are membrane, and that the chip causes only local bending stresses in the clad. The membrane stresses are computed using the computer program CYGRO-4 (Reference 1), while the benaing stresses are calculated using the program GAPI-3 (Reference 2). The numerical results of each program have been compared to test data to assure the adequacy of the modeling. In one of the following sections, the stress values uf GAPL-3 are compared to measurementis made nn an enlarged model of the cladding at a "chip" localion.

\section{MECHANICAL TESTS}

In order to calculate the bending stresses in the vicinity of a fuel ship, it was necessary to know the resistance of the chip to crushing and the resistance of the clad to radial deformation at a point load. Both of these quantities were determined experimentally, the first because of the unpredictability of the shape and crush strength of small chips, and the second becausc it was expected that the cladding radial stiffness would be a strong function of the fuel-cladding gap prior to the local distortion caused by cladding chip interaction. 
All of the tests were conducted out-of-pile at room temperature. The stresses in the cladding caused by an up-power transient are limited to avoid both plastic instability (Reference 3) and iodine stress corrosion cracking (Reference 4). During the transient, the in-pile effects of relaxation and creep are insignificant for both the fuel and cladding since the power increase rate is relatively high and stress limits are in the elastic range. Therefore, room temperature tests in the elastic range are adequate to determine both. fuel chip and cladding behavior. The test results were adapted to a fuel rod analysis by adjusting the elastic modulus for the effect of temperature.

\section{A. Crush Tests on Fuel Chips}

Two experiments were conducted on chips obtained from crushed high density thoria fuel pellets. The first experimental program was to place a chip of known size between flat, hardened steel platens and measure the load and remaining distance between the platens as they were forced together. The second program was similar except curved crushing surfaces were used so as to represent 180 degrees of the cylindrical shape of the pellet and cladding inside surface. The radius of curvature of the anvil was 0.250 inches; the ram simulating the pellet was machined to have a 0.001 inch radial clearance with the anvil or clad. Chips were placed at the bottom of the 0.250 inch curved anvil and thus were directly in line with the ram. All tests were made at a cross head speed of 0.002 inches per minute.

Pellet chips for the experiments were obtained by crushing thoria pellets (95 to 98 percent of theoretical density) and separating the debris into size categories by screening. The screened debris was then examined and individual chips selected and characterized by measuring the three major dimensions. Chips 3 mils to 9 mils in thickness and $20 \mathrm{mils}$ to $40 \mathrm{mils}$ in the other dimensions were selected for testing between the flat plates. This size of chips represents the range of sizes that could lodge in the LWBR fuel rods pellet cladiing gaps. The compressive loads were applied by use of an Instron Tensile machine.

Chips for the experiment with the curved anvil were characterized in the same way except that, in addition to size, the chips were separated into two general types of shape: (1) those with one surface curved and smooth because they were from the outer surfaces of the pellet, and (2) those from the inside of the pellet with all irregular surfaces. Chips with curved smooth surfaces 
were judged to be the most prevalent type of chip found in the fuel cladding gap and therefore were of primary interest. Chips for this series of crush tests using the curved anvil ranged from 4 mils to 18 mils thickness for the chips with all irregular surfaces, and 7 mils to 16 mils thickness for chips with a curved surface.

\section{Results and Conclusions}

Typical results of the first experiment are presented in Figure 1 . The early states of crushing, in this figure, show a rapid reduction in thickness as the load is increased to 4 pounds. For example, starting with a 5 mil chip, the thickness of the debris is reduced to $3.7 \mathrm{mils}$ when a 4 pound load is applied. However, the remainder of the debris is reduced in thickness at a slower constant rate of about 7 pounds per mil. 'l'his rate of crushing applies regardess of the original thickness of the chip. The lower slope during the early states of crushing is probably the result of high points or irregularities on the chip surtace.

Typical results from the second experiment using chips with one smooth curved surface are presented in Figure 2. They are similar to those of the first experiment in that the slopes of the curves after the initial crushing are constant and approximately the same. The curved anvil surface and the smonth and curved chip surface appear to have no effect on the chip crushing rat.e. a.t. the higher loads. Results of the second experiment for chips with a.1 1 rongh sides are not reported since the data indicated the same behavior as shown in H'igures 1 and ' 2 for the smooth surfaced chips. Therefore, neither the shane of the chip nor the curvature of the cladding had any significant effect on the crushing rate after the initial 1 to 2 mils of breakdown had occurred. After this initial condition, the data show that the load which chip debris will. support, under conditions where the debris cannot fall away or is not removed as the chip crushes, is proportional to the size of the chip and increases as the area of the debris increases.

B. Radial Stitt'ness 'l'ests on Cladding

A radial force interaction analysis between a ship and the cladding rcquires a knowledge of the radial stiffness of the cladding. As noted earlier, the stiffness would be affected by the pellet to cladding gap, therefore, a test was devised to measure the outward radial deflection of the cladding at an internal 
point load for various simulated fuel cladding gaps. The radial bending stiffness of each gap size was determined as the slope of the visual best fit line to the linear portion of the load deflection data plots.

The radial force tests were performed at room temperature on 0.572 inch outside diameter tubing with an 0.028 inch thick wall as shown in Figure 3 . In these tests, a steel mandrel of a prescribed diameter was inserted into a piece of cladding. The load was applied to the cladding interior via a $3 / 32$ inch diameter steel pin (with herispherical ends) passing through a hole in the cladding and the mandrel. As the load was applied, the cladding local diameter changes at the loaded cross section were measured with two dial gages located. as shown in Figure 3 .

The test variables are listed in the tabulation in Figure 3. Two tube lengths were included to check for' sensitivity to length as a variable. Four of the tubes were stress relief annealed (SRA) Zircaloy-4, and two tubes were recrystalized annealed (RXA) Zircaloy-4.

The measured local diameter changes and the corresponding forces were plotted to obtain the cladding stiffness for small deflections. Figure 4 is a plot of typical data from two tests plus the repeat of each. It demonstrates the lack of sensitivity of the radial stiffness to tubing length and the good repeatability of the testing procedures.

The radial force test results show a slight non-linear behavior. Some of the deformation in the tests was plastic, but it was confined primarily to the point of force application. At this point of loading, a sharp convexity (bump) was formed on the outside of the tube. The bump was generally just visible at 4 to 5 mils of diameter change and increased with increasing load. Post test measurements show that the tube diameter has plastically increased only 0.5 to 1.0 mils next to the bump, while the bump itself was generally 4 to 5 mils in height. Therefore, the load deflection data at less than 4 mils of diameter change were primarily elastic and these elastic data were used to determine the stiffness.

\section{Results and Conclusions}

The data were grouped by gap size and the radial stiffnesses were determined graphically as the slope of the best fit. line to the data. The results are shown in Table 1 below, along with a value for zero gap obtained by extrapolation. 
To provide a magnitude check on the values of stiffness determined from the data, the elastic radial stiffness of an empty cylinder with point loads was calculated. This calculation is equivalent to a test case for a very large gap and therefore would be a lower bound to the test values. This calculated value was 15 pounds/ mil and is less than the measured values in Table 1 as expected. This calculation also shows how significant the small gap is in stiffening the cladding; e.g., at a 2 mil gap, the measured stiffness is more than double the calculated stiffness of an empty cylinder with point loads.

TABLE 1. MEASURED FUEL CLADDING STIFFNESS UNDER RADIAL LOAD AT 75F

(For def'lections less thall 4 nills)

$\begin{array}{lcccc}\text { Gap (mils) } & 0 & 1.0 & 2.0 & 3.3 \\ \text { Otiffiless } & 52 & 40 & 3 c^{\prime} & 260\end{array}$

One of the tubes in the test was instrumented with strain gages. The values obtained from the gages are reported in section II.C along with comparative values from an enlarged model of the cladding at a point load.

C. Strain Tests on Fuel Rod Cladding

The fuel rod cladding is too small in diameter for extensive use of strain gayes; lherefore, an enlarged model ( $3 X$ ) of the cladding (using RXA Zircaloy), pellet, and chip was made and instrumented. The model was 5 inches long with a 1.90 inch outside diameter and a 0.092 inch thick wall. The purpose of the tests conducted using the model was to determine the applicability of the computer code GAPL-3 (Reference 2) for calculating the rladiling bending stress at a chip. GAPL-3 is an elastic plastis twn-dimensinnal (r, A) procram based on the assumption of plane strain in the axial direction. Therefore, it was not clear that this computer program would provide a satisfactory estimate of the stresses at a "point" load such as a small chip.

The assembly of the hardware for forcing the chip into the cladding, is shown in Figure 5 along with the location and orientation of the strain gages. Once the pellet, wedge, and the chip were in place inside the cladding, the set screws 
were turned clockwise to force the wedge and/or chip against the cladding. The diameter change was measured at the chip location along with the strains. The deformation was limited to prevent plastic yielding of the tube.

Two types of tests with different forms of cladding contact were conducted with the equipment shown in Figure 5. The first involved full length "line" contact between the cladding and the wedge which was accomplished by removing the chip shown in the figure and forcing the wedge evenly against the cladding with all five set screws. This type of contact provided an exact duplication of the plane strain model implicit in the GAPL-3 computer program. The test results, therefore, would allow an evaluation of the accuracy of the finite element modeling used to calculate clad strains.

The second form of clad contact was a simulation of the "point" contact at a chip in an actual fuel rod. This was accomplished by fastening a small metal chip ( 0.020 inch thick by 0.3 inch square) on the wedge at the metal pellet centerline and forcing it against the cladding with set screw No. 3. To determine if the clad strains are sensitive to the pellet length, both 1 inch and 3 inch pellets were used in this series. Clad to pellet gaps were nominally 6 and 11 mils.

\section{i. Results and Conclusions}

The measured strains and strain distribution around the cladding are presented for typical cases in Figures 6 to 10. Figures 6, 7, 8, and 10 are from the enlarged model with a nominal 6 mil cladding to pellet gap. Figure 9 presents the strains from the radial force test described in section II.B. Although not shown, the results from the 11 mil gap experiments were essentially the same as the 6 mil gap experiments.

Figure 6 presents the circumferential distribution of strains for various cladding diameter changes for the full length "line" contact case. Also show on Figure 6 as a solid curve is the GAPL-3 calculated strain distribution at 4.4 mils diameter change to be compared with the measured values (diamond shaped data points). Only one gage was operative on the inside surface for this test, but it is clear that the calculated strains are in good agreement with those measured on the outside surface except at the point of contact at zero degrees. Figure 7 presents the strain distribution for the "point" contact case (0.3 inch square chip). Note that for similar diameter changes, the strains on this figure are greater than on Figure 6 in the vicinity of the contact (zero degrees), 
but almost the same at a distance from the contact (60 degrees). Therefore, it is concluded that the strain at the contact is under-predicted by the GAPL-3 model and of the two forms of contacts, the "point" contact is underpredicted by a greater amount. This effect is again displayed in Figure 8 in which the outside surface data from three types of tests are contrasted with the CAPL- 3 calculated strains for the region of the clad near the contact. Figure 8 also shows that for the "point" contact, the strains are fairly insensitive to the length of the pellet, while there is a large effect from the form of contact.

Figure 9 presents the cladding surface strains measured on the outside of one of the radial force test specimens discussed in Section II.B. Also shown on the figure are the calculated strains. This figure supports the observation that the calculated strains are low in the contact region (10 degrees), but agree with those measured away from the contact (56 degrees). Therefore, it is concluded that the finite element modeling used for the cladding in rAFI- 3 is adequate for calculation of strain in a fuel rod for the region away from the conlact point between chip and cladding. However, strains near the contact point are underpredicted.

Fission gas (iodine) stress corrosion crack nucleation and propagation can only occur in a tensile stress field. Therefore, the cladding area of interest for rupture evaluation is the inside surface location where the maximum tensile strains occur. From Figure 7, the location of maximum strain is about 60 to 70 degrees from the chip contact point. Figure 10 displays both the maximum strains measured in this region and the GAPL calculated strains. As noted on Figure 10, the calculated values should be increased slightly to assure they agree with the measurements for the "point" contact experimental data. The strain values measured can be converted to stress values which are of most. interest for assessment of stress corrosion cracking. This jo nessibed in the next section.

III. FUEL ROD CLADDING ANALYSIS

A. Cladding Deformation and Bending Stress

The results from the previously described three tests were used to estimate the bending stress in fuel rod cladding during an up-power transient. The analytical model is shown on Figure 1l. In Part A of this figure, the interference load (L) between the chip and cladding is shown to deform the clad 
radially an amount $(u)$ while the chip is crushed an amount $\left(h_{0}-h\right)$. Here, $\left(h_{0}\right)$ is the initial radial chip height and $(h)$ is the chip height remaining.

Figure $11-B$ is a diagrammatic representation of the clad radial flexibility and the chip friability, both of which have been determined from the test data of Sections II.A and II.B. For small increments of deformation, these are assumed to be constant, and are denoted as $\frac{\Delta \mathrm{u}}{\Delta \mathrm{L}}$ and $\frac{\Delta \mathrm{h}}{\Delta \mathrm{L}}$.

By definition:

$$
\begin{gathered}
u=\frac{\Delta u}{\Delta L} L \\
h=h_{0}-\frac{\Delta h}{\Delta L} L
\end{gathered}
$$

By geometric compatibility in Figure $11-\mathrm{A}$ :

$$
D_{O}+\frac{\Delta u}{\Delta L} L=d+\left(h_{0}-\frac{\Delta h}{\Delta L} L\right)
$$

Solving for the load between chip and cladding:

$$
L=\frac{h_{0}-\left(D_{0}-d\right)}{\frac{\Delta h}{\Delta L}+\frac{\Delta u}{\Delta L}}
$$

and $L=0$ for $h_{0} \leq\left(D_{0}-d\right)$.

Therefore, combining Equations (3) and (1), the cladding deformation is:

$$
u=\frac{h_{0}-\left(D_{0}-d\right)}{\frac{\Delta h}{\Delta L}+\frac{\Delta u}{\Delta L}} \cdot \frac{\Delta u}{\Delta L}
$$

From the previously described test data and the pellet-clad geometry, the cladding radial deformation for a specified gap $\left(D_{0}-d\right)$ can now be calculated. The tensile bending stress on the cladding inside surface is then determined by the GAPL- 3 analysis model using the calculated radial deformation ( $u$ ) and gap $\left(D_{0}-4\right)$.

A more general solution to the problem can also be developed if either the clad flexibility or the chip friability is extremely non-linear. Incremental forms of the above equations can be written and the solution for ( $L$ ) and (u) obtained numerically. 


\section{B. Cladding Total Stresses at a Chip}

The cladding total stress is considered to be the sum of the membrane stress caused by pellet-clad interference and the hending stress caused by the chipcladding interference. For the situations of concern, the fuel-cladding gap is closed or nearly so, and the up-power transient causes the pellet diameter to increase sufficiently so that substantial membrane stresses (circumferential and axial) are formed. The computer analysis model CYGRO- 4 is used to evaluate the membrane stresses based on a particular history of power levels and plant maneuvers. The pellet diameter $(d)$ is also obtained from the CYGRO-4 calculation at the peak of the transient. The calculated pellet diameter includes the effects of pellet thermal expansion due to the change in power and the lifetime effects of fuel swelling and densification.

The application of Equation (4) in a situation where the cladding deformation is elastic is straightiorward. However, in the actunl case of a fuel rod, simplification must be made to obtain a practical solution. In the actual case when the fuel chip occupies most of the pellet-cl.ad gap, the clad diameter will creep down onto the chip applying a load on it and causing bending strains in the clad. It is assumed that both the radial load and bending stresses for this situation are negligible relative to those developed during a rapid transient where the cladding stresses are elastic. The mathematical equivalence of this assumption is to let $\left(D_{0}\right)$ be the cladding diameter prior to the occurrence of creep. If this assumption were not made, then the cladding bending stress would be greatly overestimated. For example, consider the clan strain if ( $\left.D_{0}\right)$ were the cladding diameter including the shrinkage due to creep. Fiven if the pellet diameter were unchanged, when Equation (4) is evaluated the clad deformation is greater than zero, and the bending strains would be those caused hy cladding creep shrinkage, not pellet thermal expansion.

\section{IV, SIMMARY}

Mechanical tests have been described which simulate the cladding bending stresses and strains due to the presence of a fuel chip in the pellet-cladding gap. The results of these tests provide useful estimates of the tensile bending stress on the inside of the fuel rod cladding in the vicinity of a fuel chip trapped between the cladding and fuel pellet. The tests and resulting calculations take into account the circumferential bending flexibility of cladding and the friability of the chip. 
Strain gage measurements on an enlarged model of the fuel pellet, cladding, and fuel chip are reported. These data are compared to the strain distributions calculated by the computer program GAPL-3. The two dimensional $(r, \theta)$ computer program calculations provide an underestimate of the maximum inside surface tensile strain in the clad for the "point" load case that occurs at a fuel chip. The model does however calculate the proper circumferential strain distribution. An engineering factor of $4 / 3$ is developed from the data to assure that the stresses in the actual fuel cladding are bounded by those calculated from the model. 


\section{ACKNOWLEDGEMENTS}

The writer acknowledges the testing and data reduction performed by N. R. Rogers to obtain the fuel chip friability, and the efforts of $N$. Ninness in performing the radial force test and obtaining the strain gage data. The contribution of $\mathrm{J}$. J. Brennan under whose management this work has undertaken in gratefully acknowledged.

\section{REFERENCES}

1. J. B. Newman, J. F. Giovengo and L. P. Comden, "The CYGRO-4 Fuel Rod Analysis Computer Program," WAPD-TM-1300, July 1977.

2. A. L. Thurman, "GAPL-3 - A Computer Program for the Inelastic Large Deflection Stress Analysis of a Thin Plate or Axial, y Symmetric Chell With Pressure Loading and Deflection Restraints," WAPD-TM-79.1, Jurie 196\%.

3. W. J. O'Donnell, "Fracture of Cylindrical Fuel Rod Ch adiding Due to Plastic Instability," WAPD-TM-651, April 1967.

4. C. C. Busby, R. P. Tucker and J. E. McCauley, "Halogen Stress Corrosion Cracking of Zircaloy-4 Tubing," WAPD-TM-1149, July 1974. 
<smiles>C1=CC1</smiles> 


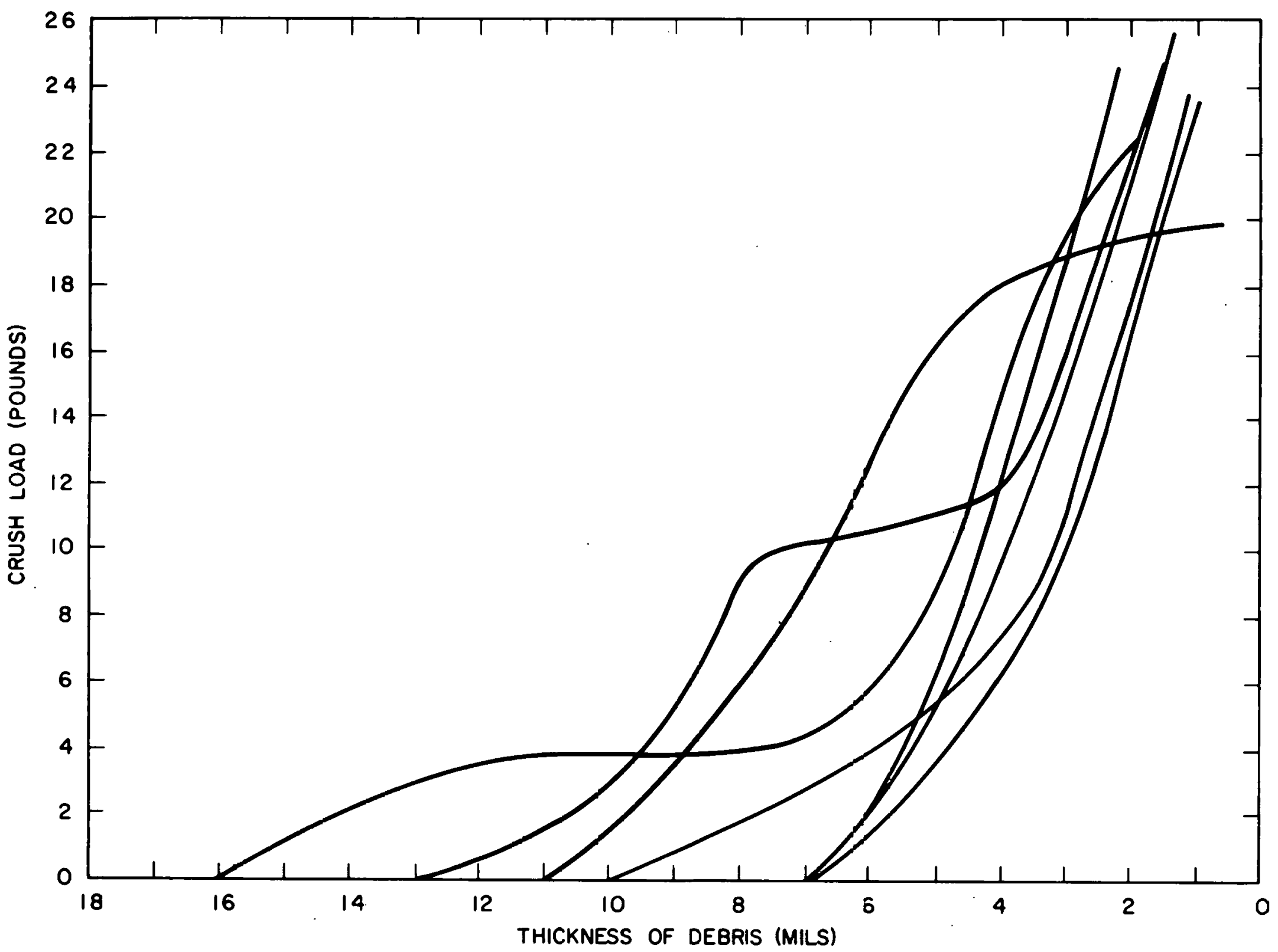

Fizure 2. Crush Force on Crips Betieen Jurved Plates (Chips had one smooth surface) 
APPLIED LOAD

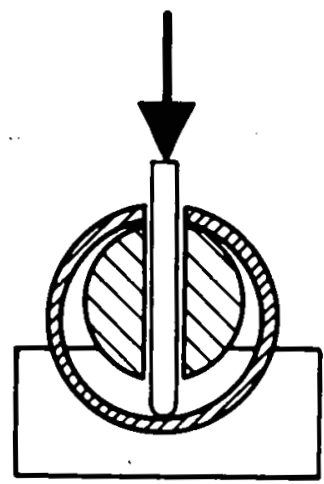

CROSS SECTION

AT LOAD

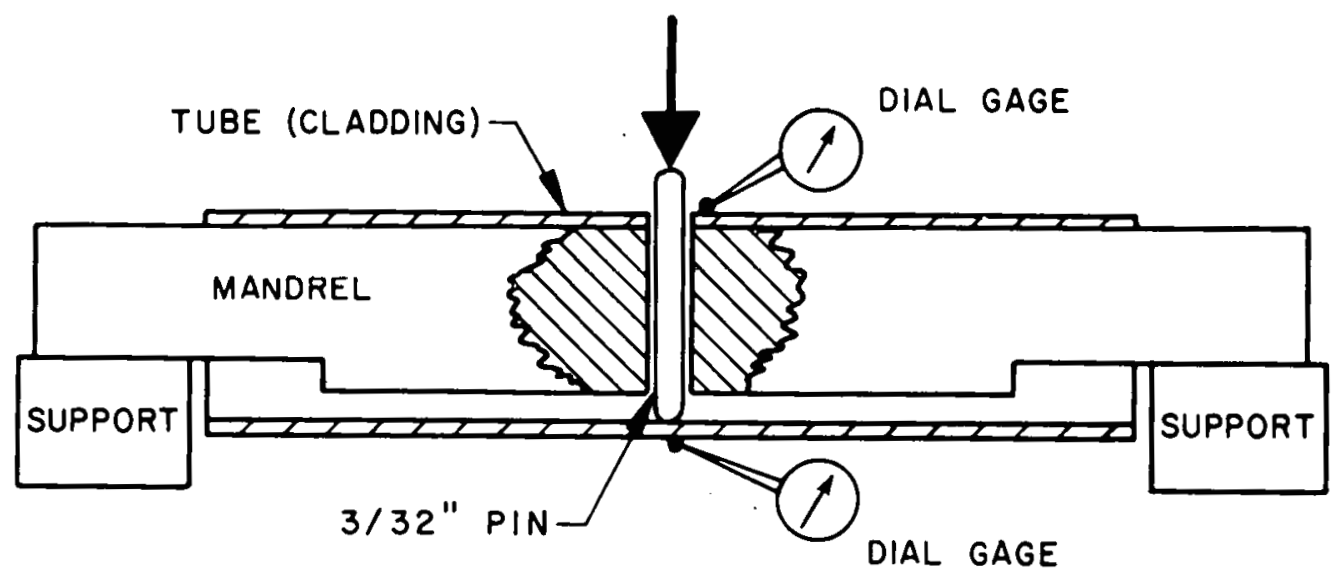

RADIAL FORCE TEST ASSEMBLY

TABLE OF TESTS PERFORMED

TEST

NUMBER

1

2

3

4

5

6
TUBE

MATERIAL

SRA

SRA

SRA

SRA

RXA

RXA
T.UBE

LENGTH

(INCHES)

2

2

4

4

4

4
NOMINAL

$\frac{\text { DIAM GAP }}{\text { MILS }}$

3.3

1.0

3.3

2.0

2.0

1.0

H'igure 3. Radial Force Test Assembly 


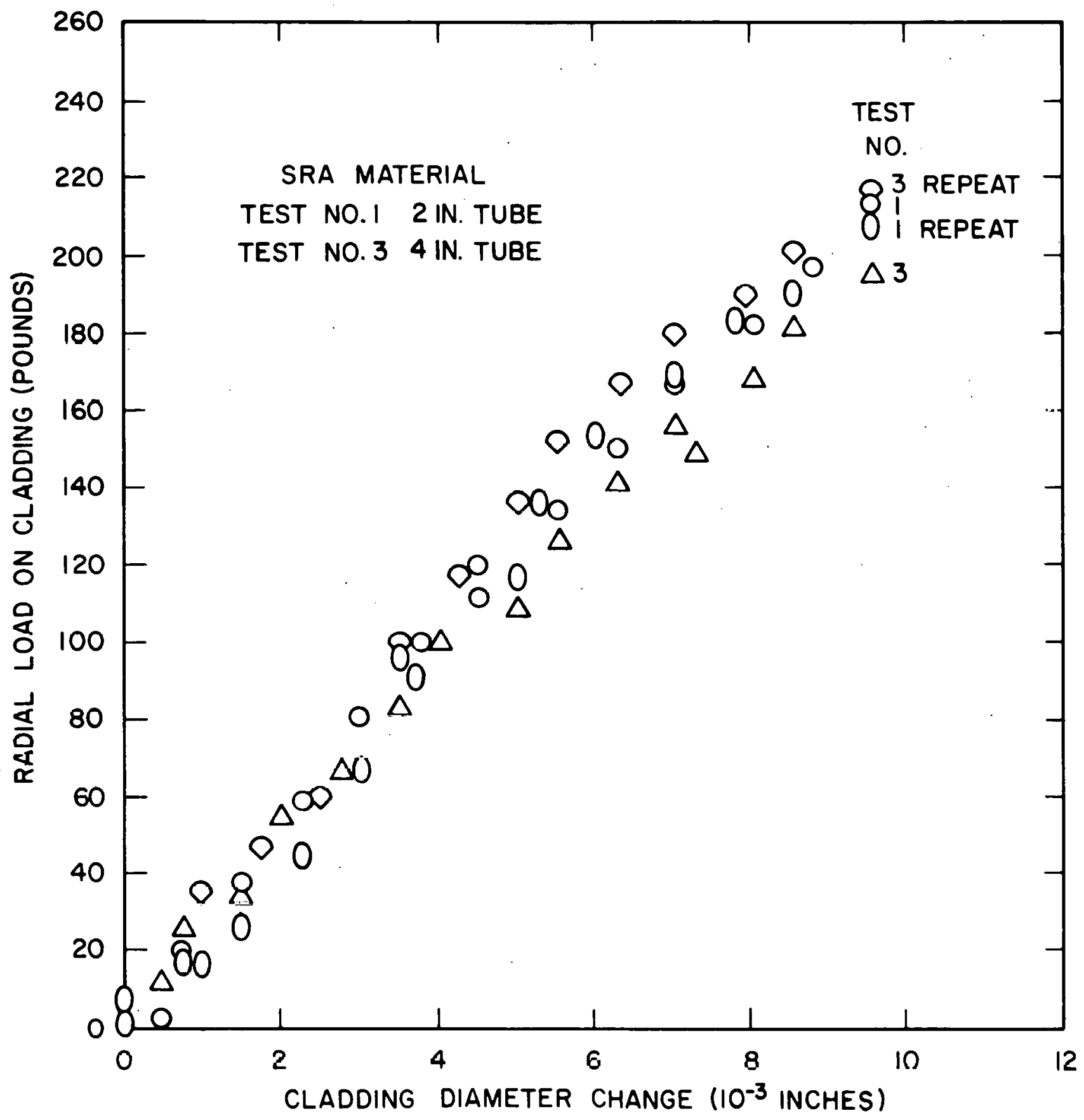

Figure 4. Radial Force Test Data ( 3.3 mil nominal diameter gap) 

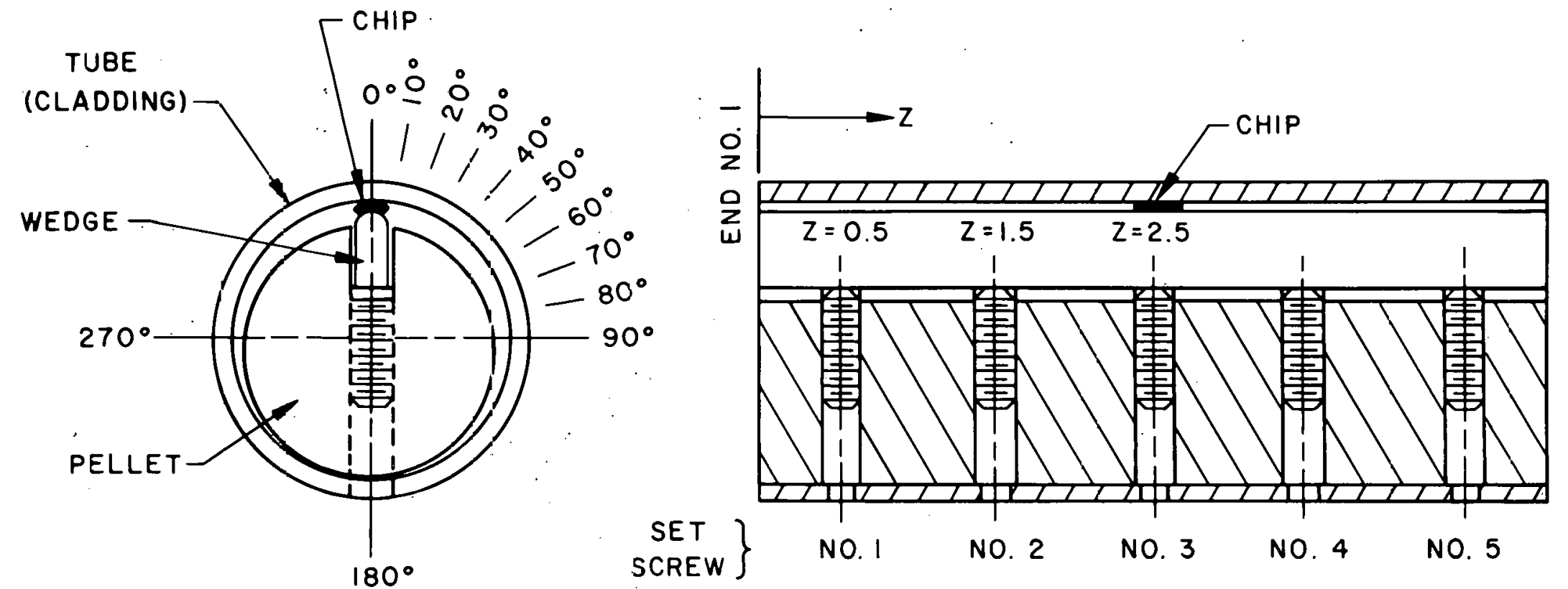

\begin{tabular}{|c|c|c|c|}
\hline GAGE & SURFACE & GAGE & LOCATION \\
\hline DIRECTION & OF TUBE & $\mathbf{z}$ & SCRIBE LINE \\
\hline HOOn & OD & $2-1 / 8$ & $0^{\circ}$ \\
\hline$A X \mid A L$ & OD & $2-1 / 4$ & $0^{\circ}$ \\
\hline HOOP & OD & $2-1 / 2$ & $0^{\circ}, 10^{\circ}, 20^{\circ}, 30^{\circ}, 40^{\circ}, 50^{\circ}, 70^{\circ}, 90^{\circ},-10^{\circ}, 10^{\circ}$ \\
\hline HOOP & 10 & $2-1 / 2$ & $40^{\circ} ; 70^{\circ}$ \\
\hline AXIAL & OD & $2-3 / 8$ & $0^{\circ}$ \\
\hline
\end{tabular}

Figure 5. Cladding Strain Gage Test Assembly 


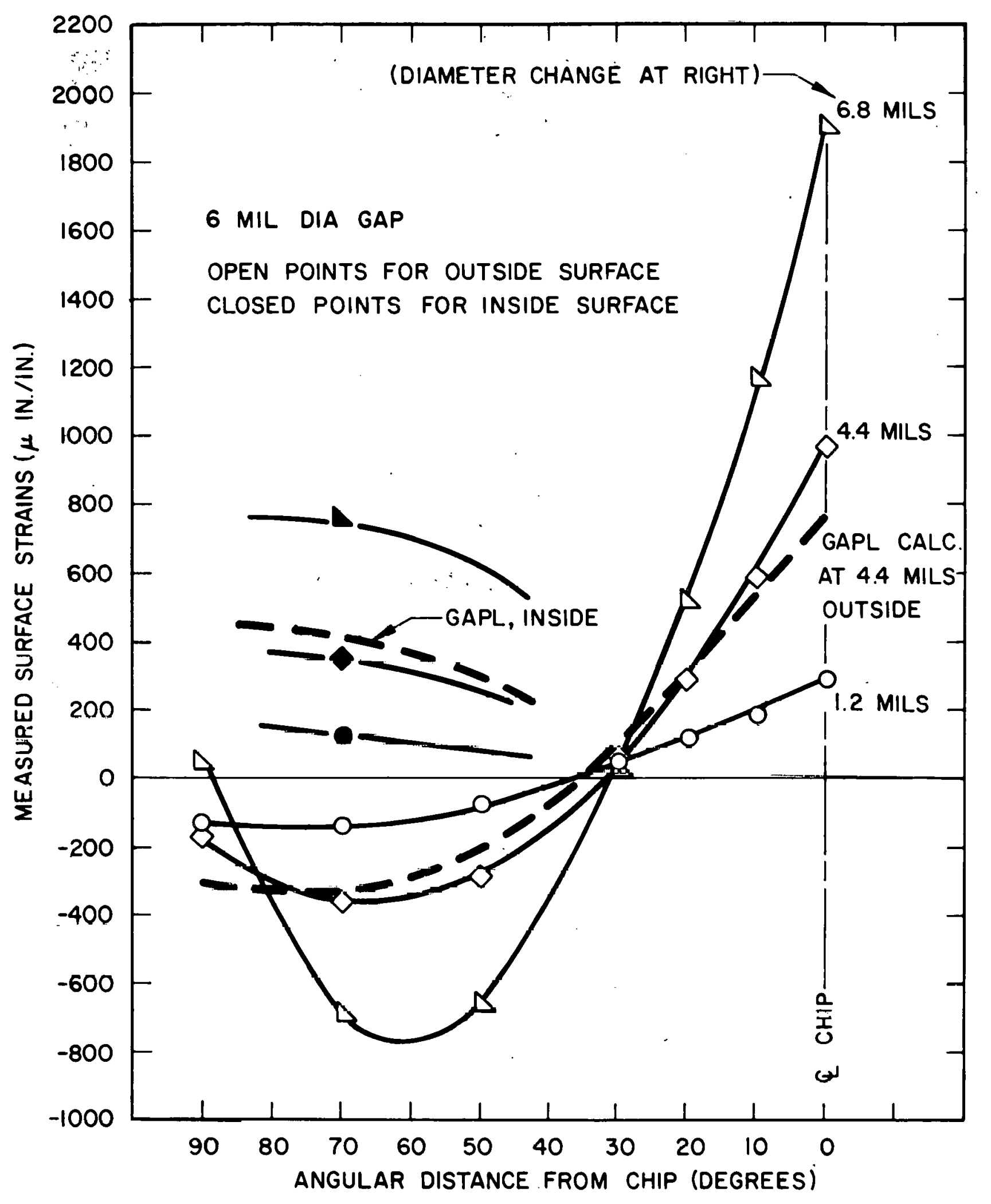

Figure 6. Cladding Strain Gage Data (Full Length Chip) 


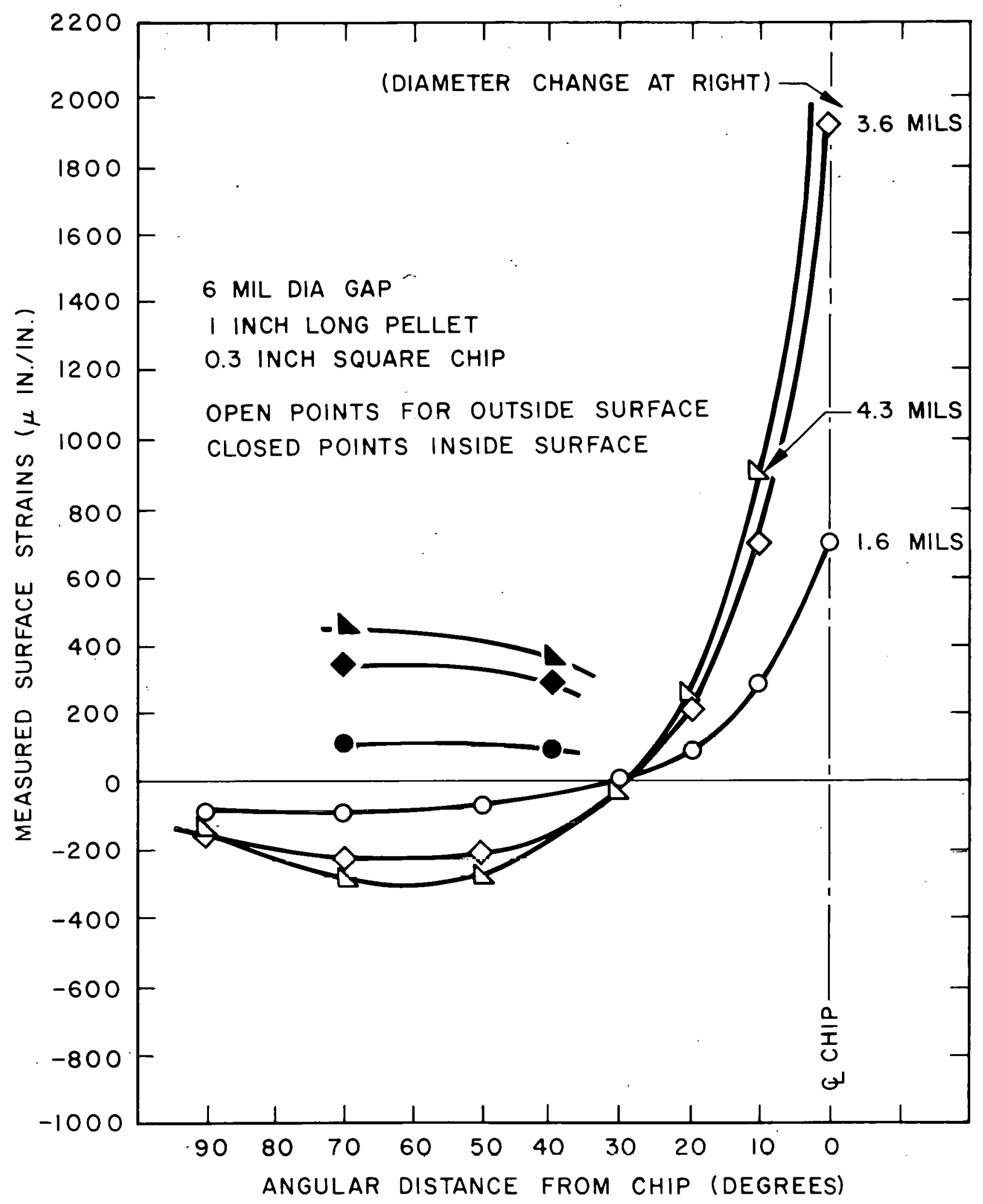

Figure 7. Cladding Strain Gage Data (Puirt Chip) 


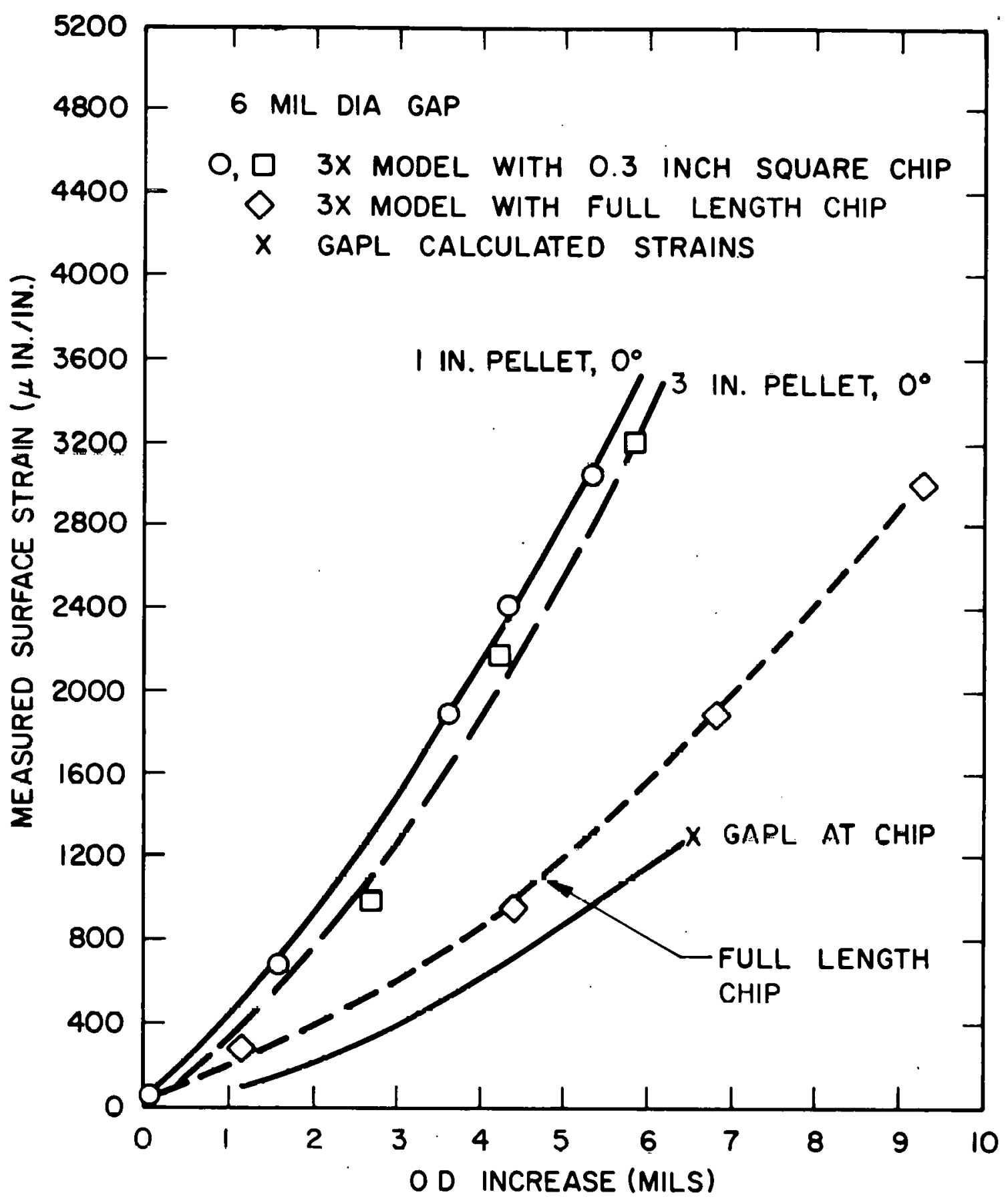

Figure 8. Calculated Tensile Strains Compared to Measured Strains (Outside Clad) 


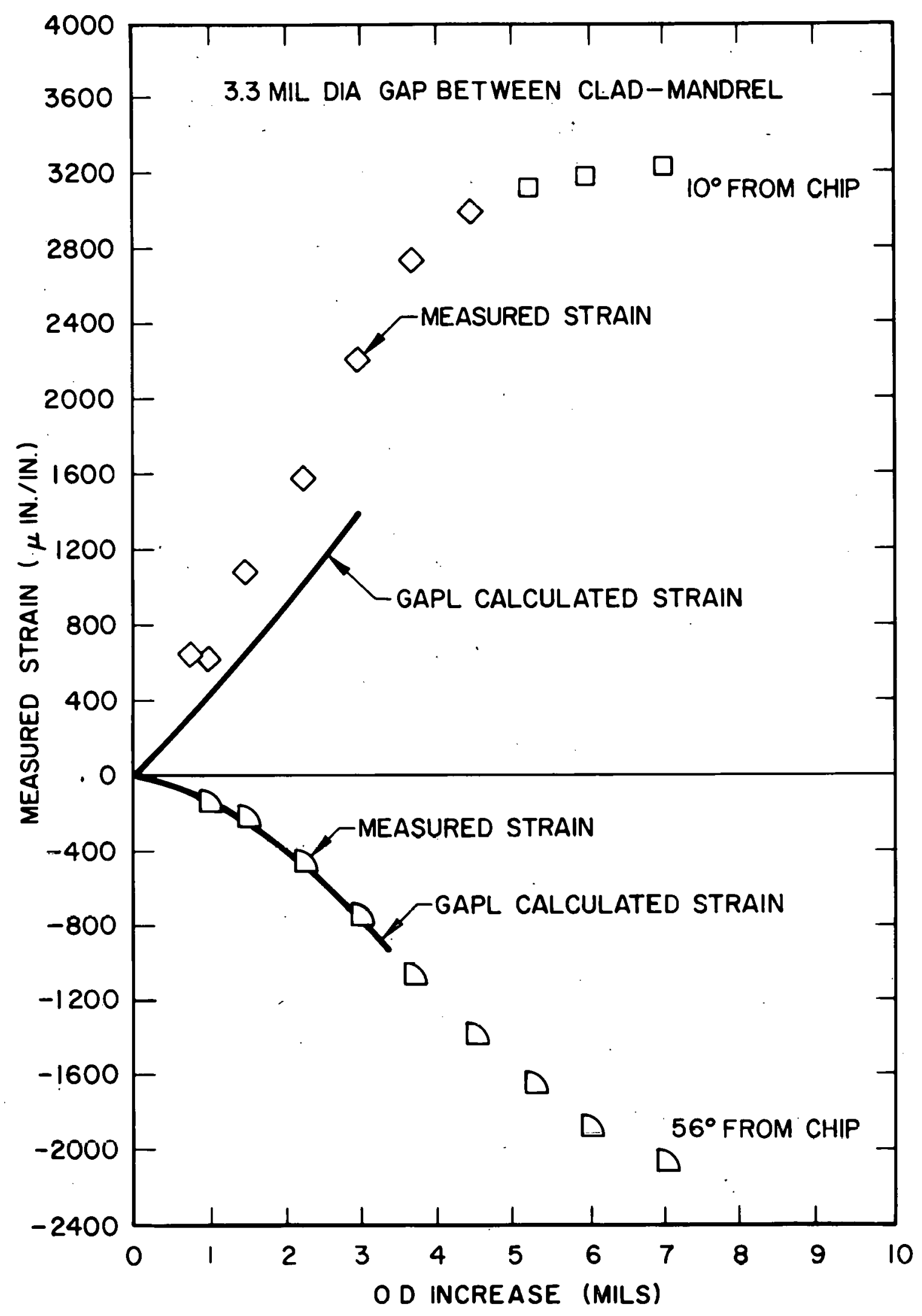

Figure 7 . Cladding Strain from Radial Force Test 


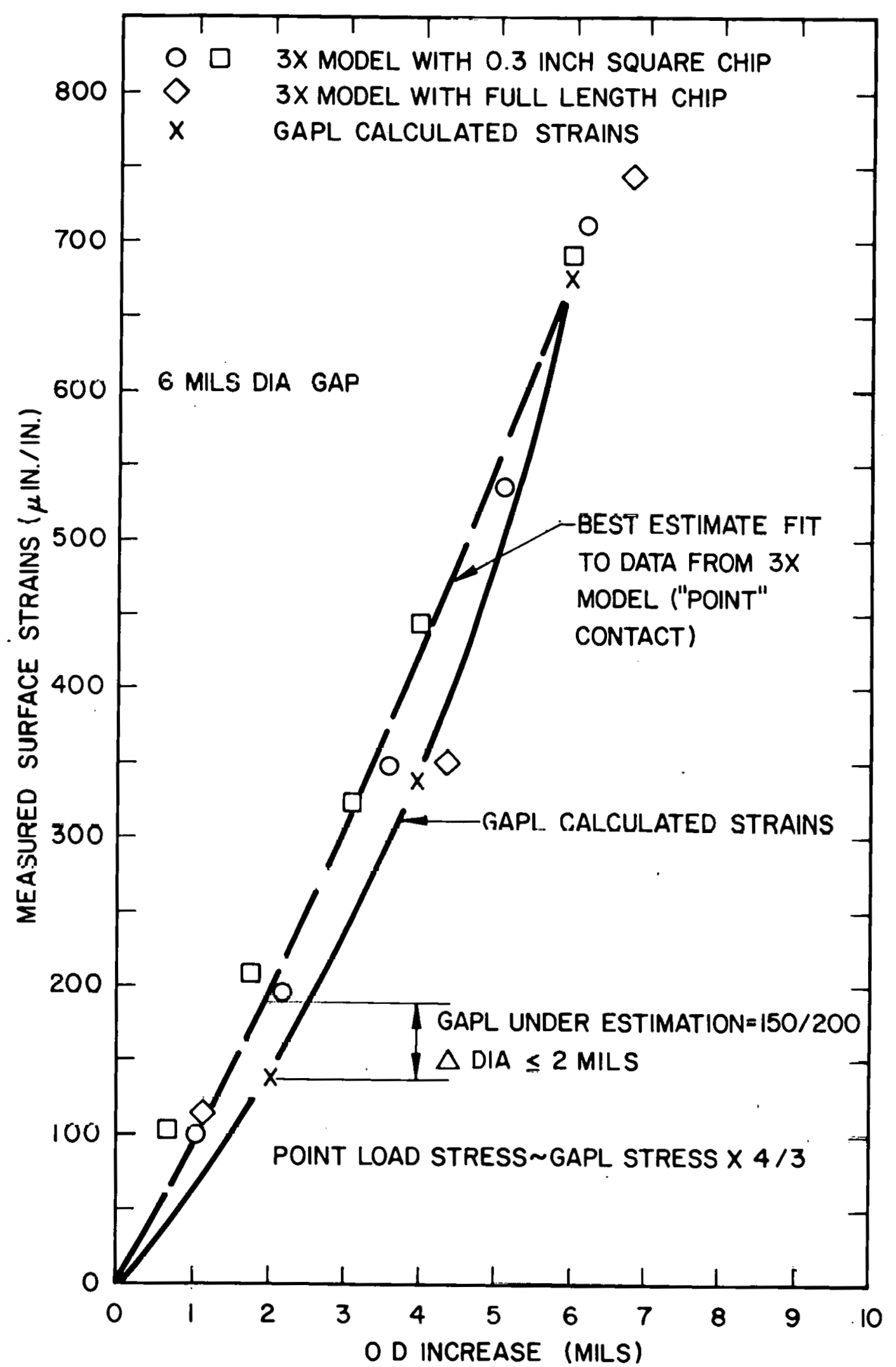

Figure 10. Calculated Strains Compared to Measured Strains (Inside Clad) 

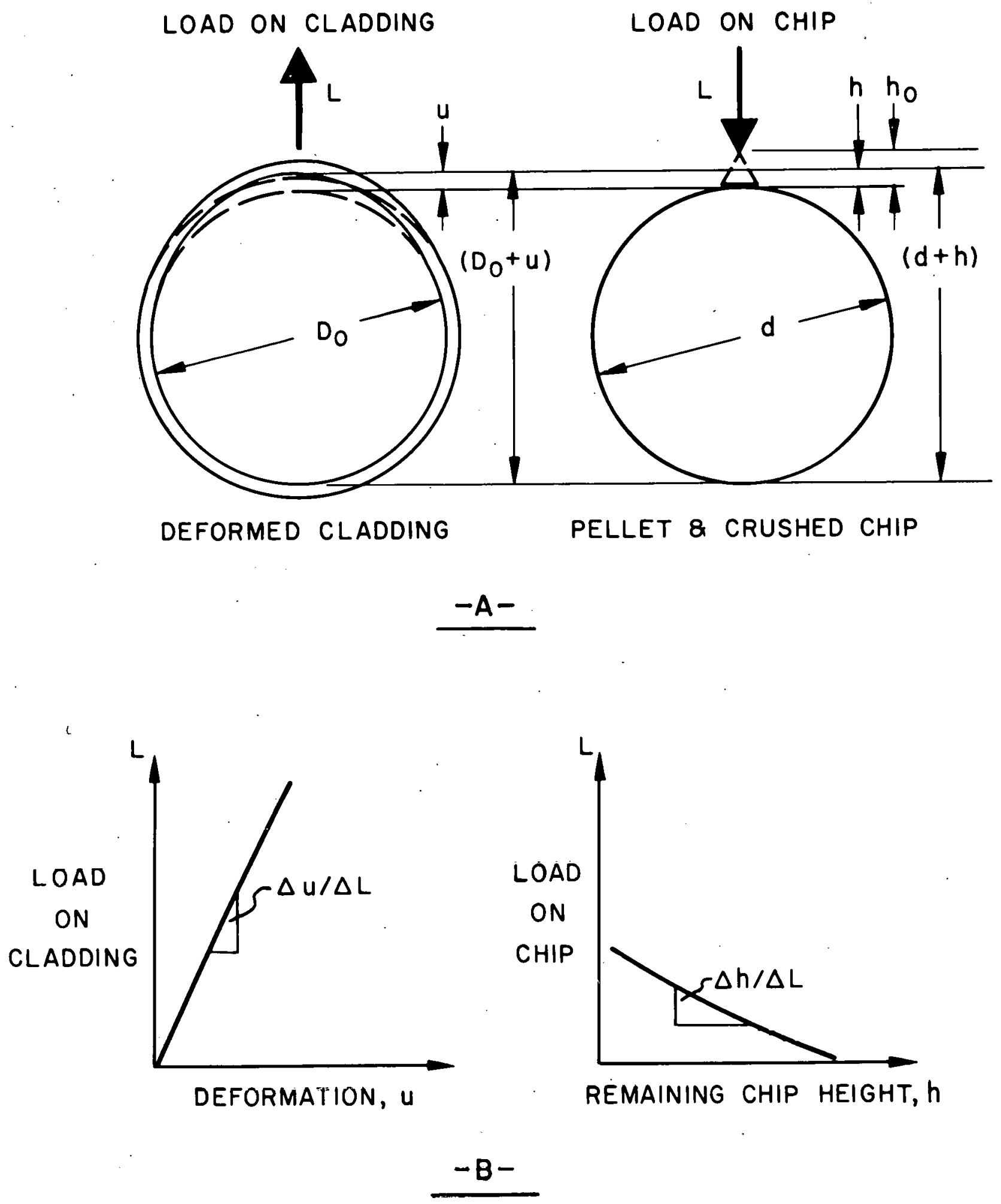

Figure 1l. Cladding and Chip Interference Model 